\title{
Quo Vadis Psikologi sebagai sebuah Kajian Ilmiah? ${ }^{1}$
}

\author{
Cleoputri Al Yusainy² \\ Program Studi Psikologi FISIP Universitas Brawijaya
}

\section{Pengantar}

Spekulasi dan refleksi mengenai pikiran, perasaan, dan perilaku manusia telah ada di sepanjang sejarah peradaban. Psikologi baru diakui sebagai disiplin ilmu yang mandiri pada tahun 1879, dengan dibukanya laboratorium psikologi eksperimen pertama di University of Leipzig. Agar mampu berdiri sebagai suatu disiplin ilmu, psikologi secara epistemik dengan demikian harus ditopang oleh fondasi filosofis yang mencakup tiga hal, yaitu empiris, positif, dan falsifiable. Empiris bahwa objek kajian bersifat nyata dan dapat diamati secara objektif, positif berarti terukur, serta prinsip falsifiability dimana setiap temuan ilmiah dapat disanggah, utamanya melalui replikasi penelitian yang dilakukan selanjutnya. Periode awal perkembangan psikologi ditandai dengan teori-teori besar dari para tokoh seperti Wilhelm Wundt, Ivan Pavlov, B. F. Skinner, dan Albert Bandura.

Sebagai sebuah ilmu yang memelajari proses mental dan perilaku, psikologi sangat berkaitan erat dengan denyut kehidupan masyarakat, mulai dari tingkat individual klinis sampai pada lingkup kolektif-komunal-sosial. Interaksi kuat antara psikologi dengan masyarakat, serta

1 Artikel ini adalah sebagian dari Orasi Ilmiah Penulis pada Dies Natalis ke-11 Fakultas Ilmu Sosial dan Ilmu Politik Universitas Brawijaya, 8 April 2015.

2 Korespondensi mengenai isi artikel ini dapat dilakukan melalui: cleo.yusainy@ub.ac.id hasil penelitian psikologi yang relatif langsung dapat diaplikasikan membawa konsekuensi yang serius, terlebih apabila terdapat masalah di tingkat fundamental yaitu penelitian dalam bidang psikologi.

\section{Psikologi kini}

Saat ini, nyaris tidak ada temuan fundamental yang dihasilkan oleh psikologi. Bahkan menurut Retraction Watch (Mar, 2015), jumlah publikasi penelitian psikologi yang ditarik dari peredaran meningkat empat kali lipat dari tahun 1989 sampai 2013. Problem yang dihadapi psikologi merentang mulai dari research misconducts sampai isu questionable research practices (QRP), pembacaan secara gegabah atas $P$ value, dan publication bias dimana jurnal ilmiah peer-reviewed cenderung mempublikasikan penelitian yang hasilnya sesuai dengan hipotesis (positive results).

Telaah Bakker, van Dijk, dan Wicherts (2012) menunjukkan bahwa proporsi positive results dalam publikasi penelitian psikologi jauh melampaui nilai wajar, mengingat secara tipikal power dalam penelitian psikologi adalah rendah. Besaran kekuatan penelitian psikologi berada pada kisaran 35\%, artinya kemungkinan memeroleh positive results hanya kurang lebih $35 \%$ saja. Lebih lanjut, menurut Fanelli (2010), positive results yang dipublikasikan dalam jurnal internasional mencapai kisaran $90 \%$. Sementara menurut Ioannidis (2012) bahkan mencapai 95\%. Dengan demikian setidaknya ada 55\%-60\% hasil 
publikasi penelitian psikologi yang patut dipertanyakan proses dan hasilnya.

Problem yang secara dramatis mengakibatkan kritik tajam terhadap status psikologi sebagai ilmu bersumber pada research misconducts. Marc Hauser (Harvard University), Diederik Stapel (Tilburg University), dan Dirk Smeesters (Erasmus University) hanyalah tiga di antara peneliti papan atas psikologi yang telah terbukti melakukan research misconducts. National Science Foundation (2001) mendefinisikan research misconducts sebagai praktik fabrikasi, falsifikasi, atau plagiarisme dalam menyajikan, melakukan, atau meninjau penelitian atau dalam melaporkan hasil penelitian. Fabrikasi data terjadi ketika peneliti menciptakan sendiri data hasil penelitiannya, sedangkan falsifikasi merujuk pada pemalsuan bahan, alat, atau proses, atau pengabaian data sehingga laporan penelitian tidak secara akurat merepresentasikan penelitian yang sudah dilakukan. Konsekuensi dari research misconducts bukan hanya ditanggung oleh pelakunya, tetapi dapat meluas pada karir mahasiswa bimbingan dan kolega yang mempublikasikan penelitian bersama pelaku, serta menyebabkan kerugian dana dan waktu bagi peneliti lain yang melakukan penelitian berdasarkan rekomendasi yang diberikan oleh pelaku (Strobe, Postmes, \& Spears, 2012).

Berbeda dengan research misconducts, questionable research practices (QRP) bersifat lebih terselubung karena berada pada wilayah abu-abu. Praktik ini analog dengan penggunaan doping dalam olah raga, dimana seorang atlet dapat memenangi pertandingan meskipun sesungguhnya ia tidak memiliki kompetensi yang memadai. Praktik QRP memungkinkan seorang peneliti memeroleh positive results padahal penelitian yang dilakukan tidak memiliki kekuatan yang cukup. Sebanyak 2.155 dosen Psikologi di Amerika Serikat yang menjadi responden survei John, Loewenstein, dan Prelec (2012) mengaku bahwa mereka pernah melakukan praktik QRP yang antara lain berupa: memilih hanya melaporkan hasil penelitian yang signifikan (67\%), tidak melaporkan semua variabel yang diukur $(78 \%)$, terus menambah jumlah partisipan di luar rencana awal sampai diperoleh hasil yang signifikan (72\%), melaporkan temuan yang sebetulnya yang tidak diduga seakan-akan sudah diprediksikan sebelumnya (54\%), dan menghapus data outlier yang setelah dianalisis menyebabkan hasil penelitian menjadi tidak signifikan (62\%).

Secara umum, praktik research misconducts dan QRP dilakukan secara sengaja disebabkan karena insentif untuk mempublikasikan positive results sering tidak sejalan dengan insentif untuk mempublikasikan hasil penelitian yang akurat (Nosek, Spies, \& Motyl, 2012). Pihak pemberi dana biasanya memberikan apresiasi yang lebih baik terhadap peneliti yang mampu memproduksi ide dan metode yang baru, serta hasil penelitian yang signifikan. Apabila hal ini tercapai, maka kesinambungan dana penelitian akan lebih terjamin. Selain itu, posisi profesor yang didapatkan dengan tidak mudah dan harus dipertahankan menjadikan praktik ini pilihan yang termudah. Dalam jangka panjang, praktik-praktik inilah yang mengakibatkan terjadinya "decline effect", dimana effect size dari sebuah penelitian justru semakin kecil dengan semakin banyaknya jumlah sampel dan replikasi atas penelitian tersebut. Dampaknya, beberapa teori mapan gagal direplikasi pada penelitian selanjutnya. Replicability adalah pilar yang menentukan kesinambungan dari suatu disiplin ilmu.

Kredibilitas psikologi sebagai ilmu juga dipertanyakan akibat kurangnya 
pemahaman peneliti terhadap konsep dasar metodologi penelitian dan analisis statistika. Beberapa ahli psikologi dunia mulai menyuarakan bahwa selama ini pembacaan atas $P$-value yang dalam penelitian psikologi dianggap palu sakral yang menentukan suatu penelitian dapat menguji hipotesis atau tidak (Null Hypothesis Significance Testing/NHST) ternyata selama ini dibaca secara keliru (Nuzzo, 2014). Bahkan jurnal Basic and Applied Social Psychology telah mengumumkan pelarangan penggunaan $P$-value untuk artikel yang dikirimkan. Secara konseptual, kegunaan $P$-value yang awalnya dikembangkan oleh Ronald Fisher bukanlah ditujukan untuk menguji hipotesis (Jerzy NeymanEgon Pearson), melainkan untuk menguji signifikansi. P-value adalah acuan untuk menolak hipotesis yang salah, namun tidak cukup untuk dipakai menyimpulkan apakah hipotesis peneliti dapat diterima.

\section{Menilik kondisi Indonesia}

Problem yang diuraikan di atas bersifat konseptual dan teknis. Di negara berkembang, dosen peneliti menjadi segmen yang paling sering ditipu oleh jurnal "predator", yaitu jurnal open access berkualitas rendah yang tidak jujur mengenai proses peer-review dan biaya untuk publikasi (Xia, Harmon, Connolly, Donnelly, Anderson, \& Howard, 2014). Beragam faktor menjadi penghambat majunya dunia penelitian di Indonesia, baik secara kuantitas maupun kualitas.

Pertama, minimalnya fasilitas penelitian yang tersedia. Keberadaan sebuah laboratorium dalam penelitian psikologi adalah jantung dari penelitian. Ketiadaan laboratorium yang memadai akan membuat penelitian psikologi berhenti berkembang karena masih mendasarkan diri pada paradigma pencil-and-paper yang berbobot ilmiah rendah. Kedua, sikap mental dosen yang menempatkan dirinya hanya sebagai pengajar, bukan sebagai peneliti atau ilmuwan. Sikap mental seperti ini akan membentuk suatu pola resistensi karena sifat ilmu sekadar hanya menjelaskan literatur yang telah usang dan menghambat produksi pemahaman baru melalui penelitian yang dilakukan sendiri secara kritis. Ketiga, kebijakan pemerintah yang mensyaratkan dosen berasal satu rumpun ilmu yang sama. Sejarah panjang psikologi tidak bisa dilepaskan dari keterlibatan ilmuwan dari beragam rumpun ilmu. Di tingkat global, penelitian bidang psikologi dilakukan dengan kolaborasi bersama dengan ilmuwan dari disiplin lain seperti neurosains, biologi, filsafat, statistika, sampai pemodelan matematika.

\section{Implikasi sosial}

Maraknya berita mengenai problem fundamental dalam penelitian psikologi menyebabkan masyarakat awam di negara maju cenderung bersikap skeptis terhadap status keilmuan psikologi. Dari 1000 responden dalam studi benchmark American Psychological Association (Penn, Schoen, \& Berland Associates, 2008), hanya 30\% saja yang setuju, "psikologi berupaya memahami perilaku manusia melalui kajian ilmiah", 52\% menyatakan, "psikologi berupaya memahami perilaku manusia dengan cara bincang-bincang." Kontribusi yang diberikan psikologi terhadap kehidupan masyarakat dianggap kurang berharga dibandingkan kontribusi dari disiplin ilmu lain seperti biologi, kimia, fisika, dan ekonomi.

Kurang responsifnya psikolog terhadap praktik kesehatan mental adalah penyebab lain munculnya skeptisme publik. Seperti halnya intervensi melalui obat-obatan (farmakoterapi), intervensi psikologis juga berpotensi menghasilkan efek samping yang membahayakan klien 
(potentially harmful therapies: PHTs). Kajian Jarrett dalam the Psychologist (Jan, 2008) mencatat ada sepertiga psikolog praktik yang tidak menyadari bahwa secara umum, 10\% klien berpotensi mengalami kondisi yang lebih parah setelah mengikuti psikoterapi dan 35\% - 40\% klien tidak memeroleh manfaat dari psikoterapi. Potensi negatif ini muncul tidak saja dalam konteks psikoterapi individual, tetapi juga dalam konteks intervensi kelompok. Kelompok remaja dengan isu conduct problems dan delinquency, serta dengan kasus penyalahgunaan zat terlarang bisa menganggap bahwa simtom perilaku yang menjadi target intervensi merupakan perilaku "normal" kelompok. Kesalahan bahkan dapat terjadi sejak awal pada level diagnosis. Penggunaan alat tes proyeksi kepribadian (seperti ink-blot) bagi populasi normal berisiko mengakibatkan $70 \%$ orang secara keliru didiagnosis mengalami gangguan mental serius.

Kalangan akademis di Indonesia bagaimanapun memiliki posisi yang strategis di masyarakat. Tingkat pendidikan yang lebih tinggi dibandingkan sebagian besar populasi, serta persepsi bahwa ilmu pengetahuan berpihak pada kejujuran dan kesejahteraan, membawa konsekuensi otoritas. Otoritas di sini adalah pendapat yang dikemukakan relatif masih dipercaya oleh masyarakat di tengah kondisi politik yang tidak kunjung membawa perbaikan yang bermakna bagi seluruh kehidupan bangsa. Karut-marut kinerja akademis psikologi menciptakan persoalan lain yang lebih luas yaitu suburnya praktik pseudoscience, pengajuan suatu konsep dengan unsur psikologis yang dikesankan ilmiah meskipun tanpa landasan teori dan hasil penelitian ilmiah yang jelas. Beberapa contoh produk yang dapat dikategorikan ke dalam pseudoscience adalah neurolinguistic programming (NLP), hypnotherapy, graphology, dan energy healing (selengkapnya lihat Lilienfeld, Lynn, \& Lohr, 2003). Ironisnya, kalangan akademis justru ikut serta mempopulerkan dan terlibat dalam praktik pseudoscience tersebut di masyarakat luas, alih-alih menjadi pengawal.

\section{Beberapa solusi}

Research misconducts dan questionable research practices telah menjadi isu nasional di negara maju. Amerika Serikat memiliki Office of Research Integrity (ORI) dan Inggris memiliki UK Research Integrity Office (UKRIO) yang bertugas untuk menyusun kode praktik penelitian, serta untuk memberikan edukasi dan pelatihan penelitian, pendampingan teknis, sampai advokasi legal. Perbaikan analisis hasil penelitian telah dirintis yaitu dengan melaporkan parameter penelitian secara lebih lengkap yang mencakup di antaranya adalah menunjukkan besaran confidence interval (CI), effect size (ES), serta power. Satu langkah besar yang juga mulai dirintis adalah dengan mengubah paradigma frequentist (NHST) menjadi paradigma Bayes, dimana paradigma ini diharapkan mampu lebih cermat dan tepat dalam menentukan apakah suatu hipotesis penelitian dapat terima (Wetzels \& Wagenmakers, 2012).

Perbaikan juga telah dilakukan oleh para aktivis sains dengan membentuk suatu gerakan global yang dinamai Center for Open Science (2013). Misi utama gerakan ini adalah untuk meningkatkan keterbukaan, integritas, dan replikasi penelitian psikologi. Budaya keterbukaan mencakup open data agar data mentah hasil penelitian dapat dianalisis ulang oleh peneliti lain, open materials agar material dan stimulus yang digunakan dapat dimanfaatkan oleh peneliti selanjutnya, dan pre-registered dimana peneliti wajib mendaftarkan desain, rencana jumlah sampel, rincian 
protokol, dan rencana analisis sebelum pengumpulan data mulai dilakukan. Replikasi penelitian yang digalakkan tidak lagi terbatas pada conceptual replication (penggunaan metode berbeda untuk menguji hipotesis penelitian yang sama dengan penelitian sebelumnya), namun justru berupa direct replication (pengulangan prosedur penelitian semirip mungkin dengan prosedur asli dalam hal peralatan, material, stimulus, dan analisis statistik). Direct replication dari Center for Open Science yang tengah diikuti research group penulis (Yusainy, Wimbarti, Nurwanti, \& Anggono, Tt.) bersama 28 research groups di Amerika Serikat, Eropa, dan Australia adalah eksperimen selfcontrol ego-depletion (lihat meta-analisis Hagger, Wood, \& Chatzisarantis, 2010). Hasil dari penelitian kolaborasi ini akan dipublikasikan bersama dalam jurnal Perspectives on Psychological Science.

\section{Penutup}

Di Indonesia, penguatan infrastruktur keilmuan mutlak diperlukan, yang secara teknis berupa menyiapkan piranti keras yaitu laboratorium yang memadai. Penelitian psikologi dengan metode kontemporer (eksperimen behavioural, neuroscience, dan data science) memiliki kualitas ilmiah lebih tinggi dibandingkan studi korelasional dengan pencil-and-paper. Sebagaimana disampaikan oleh pemenang Nobel Prize Daniel Kahneman dalam Konvensi Asossication for Psychological Science tahun 2013, metode kontemporer ini memungkinkan peneliti untuk memeroleh ratusan sampai ribuan data dari setiap partisipan hanya dalam satu kali pengukuran. Implikasinya, penelitian yang dilakukan dan hasil yang diperoleh menjadi lebih objektif, reliabel, dan akurat.
Sementara itu, dari sisi piranti lunak diperlukan; (1) sosialisasi mengenai pentingnya penelitian replikasi dan pelaporan penelitian dengan negative results, (2) peningkatan pemahaman dosen dalam hal metodologi penelitian dan teknik statistika yang benar, (3) standarisasi mutu komite etika yang bertugas menelaah suatu penelitian dari segi etika sebelum suatu penelitian dilakukan, serta memiliki wewenang untuk melakukan eksaminasi terhadap data penelitian, dan (4) peningkatan kesadaran psikolog untuk selalu memelajari dan mendasarkan praktik pada empirically supported therapies (ESTs) termutakhir guna mereduksi risiko dampak negatif intervensi psikologis. Hanya dengan langkah strategis dan sistematis dari semua pemangku kepentingan, psikologi sebagai ilmu mampu membawa masyarakat untuk hidup secara lebih baik.

\section{Daftar Pustaka}

Bakker, M., van Dijk, A., \& Wicherts, J. M. (2012). The rules of the game called psychological science. Perspective on Psychological Science, 7, 543-554. http:// .dx.doi.org/10.1177/1745691612459060

Center for Open Science (2013). Diunduh dari: http://centerforopenscience. org/

Fanelli, D. (2010). "Positive" results increase down the Hierarchy of the Sciences. PLoS One, 5(4):e10068. http:// .dx.doi.org/10.1371/journal.pone.00100 68.

Hagger, M. S., Wood, C., Chris, S., \& Chatzisarantis, N. L. D. (2010). Egodepletion and the strength model of self-control: A meta-analysis. Psychological Bulletin, 136(4), 495-525. http:// .dx.doi.org/10.1037/a0019486

Ioannidis, J. P. A. (2012). Why science is not necessarily self-correcting. Perspective on Psychological Science, 7, 
645-654. http://.dx.doi.org/10.1177/ 1745691612464056

Jarret, C. (Jan, 2008). When therapy causes harm. The Psychologist, 21, 10-12. Diunduh dari: https://thepsychologist. bps.org.uk/volume-21/edition-1/whentherapy-causes-harm

John, L. K., Loewenstein, G., \& Prelec, D. (2012). Measuring the prevalence of questionable research practices with incentives for truth telling. Psychological Science, 23, 524-532. http:// .dx.doi.org/ 10.1177/0956797611430953

Lilienfeld, S. O., Lynn, S. J., \& Lohr, J. M. (Eds.). (2003). Science and pseudoscience in clinical psychology. New York: Guilford Press.

National Science Foundation. (2001). New research misconduct policies. Diunduh dari: http://www.nsf.gov/oig/session. pdf

Nosek, B. A., Spies, J. R. \& Motyl, M. (2012). Scientific utopia: II. Restructuring incentives and practices to promote truth over publishability. Perspective on Psychological Science, 7(6), 615-631. http://.dx.doi.org/10.1177/ 1745691612459058

Nuzzo. P. (2014). Scientific method: Statistical errors. Nature, 506, 150-152. http://.dx.doi.org/10.1038/506150a.

Penn, Schoen, \& Berland Associates. (2008). American Psychological Association benchmark study. New York, NY: Author.
Retraction Watch (Mar, 2015). Tracking retractions as a window into the scientific process: Psychology retractions have quadrupled since 1989 study. Diunduh dari: http://retractionwatch.com/2015/ 03/05/psychology-retractions-havequadrupled-since-1989-study/

Strobe, W., Postmes, T., \& Spears, R. (2012). Scientific misconduct and the myth of self-correction in science. Perspectives on Psychological Science, 7(6), 670-688. http://.dx.doi.org/ :10.1177/1745691612460687.

Wetzels, R., \& Wagenmakers, E. (2012). A default Bayesian hypothesis test for correlations and partial correlations. Psychonomic Bulletin and Review, 19(6), 1057-64. http://.dx.doi.org/10.3758/ s13423-012-0295-x.

Xia, J., Harmon, J. L., Connolly, K. G., Donnelly, R. M., Anderson, M. R., \& Howard, H. A. (2014). Who publishes in "predatory" journals? Journal of the Association for Information Science and Technology. Advance online publication. http://dx.doi.org/10.1002/ asi.23265

Yusainy, C., Wimbarti, S., Nurwanti, R., \& Anggono, C. A. (Tt.). Does egodepletion exist? Multiple highpowered replications of the resourcedepletion effect. Registered Replication Report (RRR) to be published in Perspectives on Psychological Science. Diunduh dari: https://osf.io/ptzmh/ 